\title{
Students' Paraphrasing Skill in the Literature Review Section of Research Proposal
}

\author{
MUHAMMAD TAUFIQ AKBAR \\ Transbahasa Gorontalo \\ akbartaufiq936@gmail.com
}

\begin{abstract}
The issue of paraphrasing as textual borrowing in writing an academic paper draws the researcher's attention to explore the paraphrasing skill of six English Department students, Universitas Negeri Gorontalo, specifically in the literature review section of research proposal. In response to this concern, a qualitative research will be carried out. The finding revealed that among six students, three are able to execute moderate revision and the other three only produce near copy. This emerges from the difference of these students' paraphrasing output regarding to the aspects in producing a qualified paraphrasing namely the sufficient knowledge of paraphrasing, the capability in analytic reading and its correlation in applying paraphrasing strategy, and also the citation mechanic. Therefore, the finding suggests the necessity to expand students' concept about paraphrasing in reviewing literature by improving their skill with guidance from related institutions. Moreover, it is recommended to undertake further research about paraphrasing in wider scope due to investigate possible issues related to paraphrasing and the other textual borrowing mechanics.
\end{abstract}

Keywords: Paraphrasing, Literature Review, Academic Writing.

\section{INTRODUCTION}

The issue of paraphrasing as the aspects of academic writing becomes major concern to several researchers lately. In spite of view paraphrasing as the habit of textual borrowing, students consider paraphrasing as the act of plugging in synonym. Hence, it affects the results of paraphrasing which should be addressed as the results of critical and analytical reading than the results of writing output. Paraphrasing is focused on one's knowledge transforming capability rather than knowledge sharing (Bailey, 2006) which needs one's engagement to integrate the source text into the output of paraphrasing (Amsberry, 2010; Liao \& Tseng, 2010). The insufficient of students' understanding regarding to the previous paraphrasing concept might lure students to do "patch writing". The term patch writing, according to Howard (as cited in Howard, Serviss, and Rodrigue, 2010), is the way of substituting the synonym, structure, and deleting some words from the source text (p. 178). This action is, mostly, committed by someone who has insufficient language skill, specifically in both reading and writing.

Accordingly, putting the proper mechanic of citation is considered as the important aspects of paraphrasing. Putting proper citation shapes the output of paraphrasing. Several researchers argue that a decent mechanic of citation will produce a successful paraphrasing attempt as well (Liao \& Tseng, 2010; Mahmood, Mahmood, Muhammad, Allaha, 2010; Rabab'ah \& AlMarshadi, 2013).

Considering that little is known about English Department students' paraphrasing in research proposal despite that the prior issue of paraphrasing in academic writing scope is also ensue in the English Department. Take a case on the students who are going to compose scientific paper. Based on researcher's observation, the English Department students have inadequate paraphrasing results especially in the literature review section of research proposal. 
Hence, the current study attempts to explore students' paraphrasing skill in literature review section, focused on the research proposal.

Furthermore, this research is also expected to give some beneficial to the reader, especially for students in comprehending an adequate paraphrasing as textual borrowing in literature review. Also, further researchers who are going to conduct similar research in different framework may use this study in providing relevant literature.

\section{LITERATURE REVIEW BASIC CONCEPT OF PARAPHRASING}

Essentially, paraphrasing refers to the process of re-delivering the ideas in one's own language. Several researchers defined paraphrasing as the act of restating information by integrating the linguistics features (the semantic and syntactic component) such as synonym substitution, changing the word form, and re-arrange the sentence structure (Kissner, 2006; Badiozaman, 2014). In addition, Driscoll and Brizee (2011) label the term paraphrasing as "your own rendition of essential information and ideas expressed by someone else, presented in a new form" (para.2). However, the message from the original excerpt must be retained in the output of paraphrasing (Higher Score.ca). Furthermore, ignoring citation mechanic is not allowed in paraphrasing (Campbell, as cited in Hirvela \& Du, 2013, p.88).

\section{PARAPHRASING IN REVIEWING LITERATURE}

As the aspect of writing in academic situation, paraphrasing contributes to the process of reviewing literature. The essence of literature review and paraphrasing refers to the process in reviewing literature. During writing a literature review section in research proposal, one must be able to gather and synthesize a number of data (Acheson \& Bond, 2011). It refers to the definition of literature review which is defined as "critical, analytical summary and synthesis of the current knowledge of a topic. It should compare and relate different theories, findings, and so on, rather than just summarize them individually" (Harvey, 2010). Furthermore, the literature review provides a research's justification from the integration of multiple documents in a specific topic (Jaidka, Khoo, and Na, 2011, p. 467). Hence, the textual borrowing activity is necessary to put the results of one's critical thinking, particularly paraphrasing (Amsberry, 2010; Howard, et.al, 2010).

The necessity to involve paraphrasing in literature review emerges from the nature of paraphrasing as source-based writing that is quite complex Hirvela \& Du, 2013). It is not as the same as taking the word from the sentence (Roig, 1997). According to Bailey (2006), "paraphrasing involves changing a text so that it is quite different from the source, while retaining the meaning" (p. 29). Thus, writers must be able to demonstrate an in-depth understanding toward a text before they start to paraphrase certain passage, consider the writers' engagement to the reading passage text (Barry, 2006; Ho, 2010; Liao \& Tseng, 2010; Sun, 2012; Badiozaman, 2014). This aims to produce accurate results of paraphrasing by retaining the message from the original excerpt (Badiozaman, 2014)

\section{ISSUES OF PARAPHRASING IN REVIEWING LITERATURE LACK OF PARAPHRASING AS TEXTUAL BORROWING CONCEPT}

A number of issues regarding paraphrasing concept were already addressed by some researchers. Noticeably, Roig (1997) stated that the term "restatement to your own word" as the basic concept of paraphrasing lead students to the misuse of paraphrasing in academic writing context. Further, this may be the factor of committing a "patch writing", a term explicitly stated by Howard, who is describing about the way of substituting the synonym, structure and deleting some words from the source text (as cited in Walker, 2008, p.387). 
Despite of facing the risk of plagiarism, however, patch writing is also can be regarded as the act of learning, particularly for the ESL students (Roig, 1997).

In attempt to solve the problem regarding to the students' concept of paraphrasing, Barry (2006) reveals that graded paraphrasing practice to students can improve both the borrowing skill and perception about what plagiarism is. Similar to prior study, Walker (2008) suggested that unintentional plagiarism can be prevented by constructing an effective and acceptable paraphrasing through practice. Offers a specific method is also an effective effort in enhancing students' comprehension regarding the appropriate text borrowing (Ho, 2008). Further, Amsberry (2010) recommended to some stakeholder, for example the librarian, might take parts in developing students' understanding regarding the mechanics of borrowing.

\section{UNDERSTANDING THE SOURCE TEXT}

Several researchers addressed the issue of students' understanding toward the text and its impact to the output of paraphrasing. For instance, Sun (2012) depicted that the level of readability of text has the impact of one's writing. The higher the context of a passage has a high potential for students to commit exact copying in their paraphrasing (Badiozaman, 2014). In accordance to this, Howard et.al (2011) argued that writer might have difficulties to understand the source which impacted to the quality of paraphrasing. Pecorari (as cited in Lankamp, 2009, p.1) stated that the outcome of poor paraphrasing caused by the "confusion and inaccuracy during the note-taking process.

In addition to the factor of insufficient linguistics competence, the lack of practice and actual experience in applying the skill impacted to one's effort in paraphrasing as the textual borrowing activity (Liao \& Tseng, 2010). For instance, Bissett (2012, p.2) stated that a bad paraphrasing implemented a small amount of techniques of writing from sources; it means that one does not fully comprehend the passage that they will put in their own paper. In other words, the inability to comprehend the texts is the factor in producing a qualified paraphrasing (Barry, 2006). Accordingly, Maharsi (2011) implied that those who are engaged in writing for academic purposes have better understanding toward the reading material.

\section{CITATION MECHANIC IN PARAPHRASING}

In addition to the factor of lack competence of textual borrowing practice, an insight of citation mechanic might affect one's writing, in particular to this aspect beside the linguistics competence of a student (Amsberry, 2010). Some researchers assume that the referencing mechanic shapes the output of paraphrasing as well. This is due to the influence of the application of putting proper citation in paraphrasing, in refers to the output of the writing. Regarding to several research results, a decent paraphrasing is, generally, involves proper citation mechanics. (Liao \& Tseng, 2010; Mahmood, Mahmood, Muhammad, Allaha, 2010; Rabab'ah \& Al-Marshadi, 2013).

Likewise, a study carried out by Lankamp (2009) finds "the ignorance of the rules and lack of authorial identity is happened to be the factors that causing plagiarism". The researcher argued that ignoring the rules means that the writer already knows that there are some mistakes in the citation format within the work, but it is left as the way it is without any correction. The case of ignoring the rules might be omitted either intentional or unintentional, whether the writer admits it or not, it can be seen in the paper (Liao \& Tseng, 2010). 


\section{PARAPHRASING STRATEGY}

Several experts argue that paraphrasing is not a matter of replacing and changing either word or structure of sentence (Barry, 2006; Ho, 2010; Sun, 2012; Bissett, 2012; Hirvela \& Du, 2013; Badiozaman, 2014). There are several articles discussed about the technique to paraphrase properly, however, it has similarity from one to each other. According to the article of USC Aiken (2011), there are several strategies of paraphrasing, which are: using synonym, changed varied sentence patterns, changing the order of idea, shortened a long idea, changing the abstract idea into the concrete one as explained as follows.

\section{ALTERING WORDS AND RE-ORGANIZED SENTENCE'S PATTERN}

First strategy is altering some words. This is the common and basic strategy of paraphrasing that all students know. The word from original statement will be replaced with an appropriate synonym in the paraphrased version. However, overusing this strategy too much will affect the quality of paraphrasing, also it can be considered as plagiarism, and even it has a quotation mark in the passage. Commonly, students tend to apply this method because of the lack of vocabulary. Hence, the reader will be unable to understand the entire passages resulting in the minimal strategies used in the work.

Secondly, one may also re-structure the sentence pattern. However, re-arrange the structure of a sentence must still retained the meaning is also strategy of paraphrasing. Basically, writers will modify the grammatical structure of a passage during this process as depicted in the following example.

\section{CHANGING THE ORDER OF INFORMATION}

Changing the order of information, as long as it does not altering the meaning of original passages, is allowed in paraphrasing. However, reorganizing the order of a passage is applicable only to a sentence which has more than two kernels as depicted as the following.

\section{WORD DELETION}

Simplified a long sentence into a shorter version is allowed in paraphrasing. Howard (as cited in Badiozaman, 2014) categorized this strategy as deletion. Novice writers are commonly having a problem to distinguish this strategy with summary. However, one should bear in mind that paraphrasing and summarizing are different, yet similar. Paraphrasing still provide the detailed information from its origin, while summary tend to depict the main information or the gist by deleting several minor details from the sources.

\section{MODIFY THE ABSTRACT IDEA INTO A CONCRETE ONE}

Changing an abstract idea becomes a concrete version also useful in paraphrasing. This does not mean that the idea is drastically changes. Instead, this only modifies the idea by using another relevant statement which is sync each other. Therefore, one must cautiously if they want to involve this strategy in their paraphrasing. Otherwise, the message of the source text will not deliver successfully in the paraphrasing result. The following table presents the example of paraphrasing by modifying the ideas (Based on the sample from van Emden, as cited in Bissett, 2012). 


\section{TAXONOMY OF PARAPHRASING}

In exploring one's paraphrasing, a specific taxonomy was used by Keck (2006) to categorize the paraphrasing quality. This taxonomy examines one's paraphrasing by sentence. Firstly, the sentence from the original passages is compared to the paraphrasing attempt to count the total similar words in both passages. Moreover, the additional categories are provided in assessing one's paraphrasing based on the strategies of paraphrasing such as the grammatical changes and the way of involving writer's own elaborative phrases. Based on the comparison of both passages, Keck divided the paraphrasing quality into four categories such as near copy, minimal revision, moderate revision, and substantial revision. However, this study will adopt the Keck's taxonomy based on Badiozaman's modification taxonomy (Badiozaman, 2014).

The taxonomy of paraphrasing in Badiozaman's model is considered as the appropriate model to qualifying EFL students' paraphrasing as opposed to the original taxonomy was purposed to analyze the advanced students' writing. The difference between the original and modified taxonomy is the classification of paraphrasing types. In Badiozaman's modified taxonomy, the classification is divided into two types rather than four types in the original one, still the analysis of one's paraphrasing is almost the same as the Keck's model.

Regarding to numerous generalizations from several researchers, it is interesting to explore students' paraphrasing skill as textual borrowing concept. The current study will present an analysis of students' paraphrasing within the literature review section of a research proposal. This refers to the English Department students' paraphrasing in the writing from source context, specifically in the literature review of research proposal. The relevant literatures which have been reviewed and the taxonomy of paraphrasing will be the tool in examining students' paraphrasing output in the current research as well as depicting the results and providing discussion in the further section.

\section{METHODOLOGY OF RESEARCH METHOD}

The study was undertaken by applying a qualitative method. A qualitative or the interpretive study is a method to depict the data interpretation (Lodico, Spaulding, Voegtle, 2010, p. 142).

\section{SITE AND PARTICIPANTS}

The study took place in English Department in State University of Gorontalo. Six students that already composed their research proposal as the representative from three subfields of language research in this department was randomly selected as the participant. They must already pass proposal examination, also a number of subjects related to writing and research, i.e., Writing 4, Research on Language, and Seminar on Language. In addition, the numbers of selected proposals are appropriate with the requirements of the current study as the data that will be gathered from these papers already sufficient to be analyzed further.

\section{THE DATA}

The primary data of the current research was several paraphrased pieces from the literature review section of research proposals. The secondary data was the original source that the students take as reference in their proposals. In addition, an interpretation from the interview became the secondary data to support the analysis. 


\section{PROCEDURE IN DATA COLLECTION}

The techniques of data collection of the current study were documentation and interview. There are five questions in the interview as follows.

1. According to some literatures you have read, what is paraphrasing?

2. How many strategies of paraphrasing do you know? Which one of those strategies that you use the most?

3. When paraphrasing, are you concerned about the rules of citing?

4. What do you think about plagiarism?

5. What do you think about the paraphrasing in reviewing literature?

\section{TECHNIQUE OF ANALYZING DATA}

Once the data are collected, the process of data analysis started. The steps of analyzing data were divided into three steps which are identification, coding, and conclusion. The following is the explanation of each data analysis technique.

\section{IDENTIFICATION}

Firstly, all paraphrasing passage from students' literature review were collected to obtain the data. The passage were selected meticulously due to avoid the ambiguous data. At this case, the possible paraphrased passage was compared to the original text. The criteria of the paraphrased passage was used to ensure that the selected passage is classified as paraphrasing, not summarizing. Furthermore, the primary data was displayed. These refer to the students' paraphrasing output and its original text.

\section{CLASSIFICATION}

Classifying the data was conducted once the primary data were identified. The displayed data was compared with the secondary data or the original passage from the reference. At this step, total strategies of paraphrasing students applied was classified based on the prior step. Furthermore, the Keck's taxonomy of paraphrasing in Badiozaman's model was used to examine students' paraphrasing attempt in detail (Badiozaman, 2014). The classification was divided into two categories, near copy and moderate revision by examining the total strategy of paraphrasing used in a sentence and the similarity in both the original excerpt and students' paraphrasing passages.

The following table depicts the Keck's paraphrasing taxonomy based on Badiozaman modified model.

Table 3.1 Keck's Taxonomy of Paraphrasing Based on Badiozaman's Modified Model

\begin{tabular}{ll}
\hline \multicolumn{1}{c}{ Paraphrasing Types } & \multicolumn{1}{c}{ Description } \\
\hline Near Copy & $\begin{array}{l}\text { Composed long copied words from the original sentence. } \\
\text { Borrowed entire clause from the original sentence. } \\
\text { Moderate Revision }\end{array}$ \\
& $\begin{array}{l}\text { Made a number of lexical and grammatical changes to the } \\
\text { original. } \\
\text { Contained the writers' own elaborative phrase or clause. }\end{array}$ \\
\hline
\end{tabular}

One's paraphrasing will be categorized to the type in the taxonomy if it meets to the written description. For instance, one's paraphrasing will be classified as near copying if the output mostly consists of similar words (with the exception of proper noun, or common knowledge 
phrases which are unable to be replaced) to the original excerpt and no other strategy of paraphrasing applied but the synonym substitution. In addition, if a passage applied additional strategy (i.e modifying idea, information re-order) and there are some lexical and grammatical changes, the paraphrasing is categorized as moderate revision.

\section{CONCLUSION}

Afterward, the interpretation from the interview was used as the consideration from the results of prior phase. The interview transcripts from students act as the secondary data in discussing and summing up the study. At this step, students works were matched with their opinion from the result of interview. Several points to be considered in both of the transcript and the paraphrasing output are the general knowledge of paraphrasing, the understanding of paraphrasing strategy, and the additional insight of involving proper citation. Moreover, the results of the previous step were discussed thoroughly by considering several reviewed literatures in this proposal. And hence, a conclusion was explained based on the previous processes.

\section{FINDINGS AND DISCUSSIONS FINDINGS}

The findings in this research emerge from the data of six English Department's students' selected research proposal, the paraphrasing and the interpretation of the interview. The first is the students' paraphrasing attempt and its classification based on the paraphrasing taxonomy. This finding is discovered by examining the paraphrased version and the original source in the literature review section. The second finding is the students' interview results regarding their paraphrasing insight. This encompasses the participants' comprehension of paraphrasing in essence, the strategy of paraphrasing they used in literature review as well as the implementation of in-text citation and their awareness of the plagiarism issue, as well as their difficulties in the paraphrasing process.

The following table depicts the overall findings of the participants' paraphrasing classification, based on the application of Keck's modified paraphrasing taxonomy by Badiozaman (2014), in literature review section.

Table 4.7 Classification of Participant's Paraphrasing Output

\begin{tabular}{|c|c|c|}
\hline Participant & Strategy of Paraphrasing Used & Classification of Paraphrasing \\
\hline First participant & $\begin{array}{ll}\text { - } & \text { Synonym substitution } \\
\text { - } & \text { Word deletion }\end{array}$ & Near copy \\
\hline Second participant & $\begin{array}{l}\text { - Lexical change to the phrases } \\
\text { - Word deletion }\end{array}$ & Near copy \\
\hline Third participant & 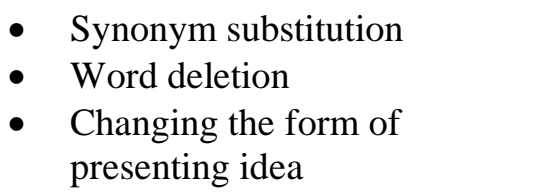 & Moderate revision \\
\hline Fourth participant & $\begin{array}{l}\text { - Synonym substitution } \\
\text { - Changing the form of } \\
\text { presenting idea } \\
\text { - Word deletion }\end{array}$ & Moderate revision \\
\hline Fifth participant & $\begin{array}{ll}\text { - } & \text { Synonym substitution } \\
\text { - } & \text { Word deletion }\end{array}$ & Near copy \\
\hline
\end{tabular}




\begin{tabular}{|c|c|c|}
\hline Sixth participant & $\begin{array}{ll}\text { - } & \text { Synonym substitution } \\
\text { - } & \text { Word deletion } \\
& \text { Changing the form of } \\
& \text { presenting idea }\end{array}$ & Moderate revision \\
\hline
\end{tabular}

Based on the table 4.7, the six students is classified into two groups which are the decent and poor paraphrasing as reflected in their paraphrasing output. The decent paraphrasing group, consist of the third, the fourth, and the sixth participant perform better in attempts of paraphrasing and the comprehension regarding paraphrasing as textual borrowing concept. Most of these participants' paraphrasing output applied three paraphrasing strategies which are the same strategies from one to each other. In terms of the engagement toward the text, these three students are able to put more effort in grasp the keyword of the original sources that their paraphrasing involves own phrases in spite of the synonym replacement. Moreover, the decent group is seemed to be aware of preventing the issue of plagiarism in paraphrasing, as it has no issues on citation mechanic in their paraphrasing results and the interpretation of interview.

They are opposed to the rest three of the participant (the first, second, and fifth participants) which applied fewer strategies within their paraphrasing output. Furthermore, these participants have equal paraphrasing quality because there are several words in their output of paraphrasing with the original text compared to the total of similar words in the decent group students. Additionally, the lack-group students' paraphrasing almost contain the entire clause from the excerpt either imitate the style in their paraphrasing results. This is, more likely, due to their minimum effort to comprehend the source text. As for the involvement of proper citation mechanic, these lack-group students are similar to the decent group that there are no citation issues on their paraphrasing output based on the same consideration to the previous group. They are seemed to be addressed the issue of plagiarism in paraphrasing as the effort in retaining the authorship rather than the intertwining of the authorship and the process in producing decent paraphrasing aspect.

\section{DISCUSSION}

Once analyzed the data from six research proposals of English Department students paraphrasing and the interpretation of the interview, this research reveals a complexity in students' paraphrasing skill. There are two categories of students' paraphrasing which are near copy and moderate copy based on Keck's modified paraphrasing taxonomy by Badiozaman (2014). accordingly, the findings from the students' paraphrasing result also the interpretation of interview report that a decent paraphrasing skill encompasses several points such as one understanding to the concept of paraphrasing, the interconnection between the understanding and the output of paraphrasing, the comprehension to the source passage, and the influence of mastering mechanic of citation. Thereby, this finding is echoing results seen in Howard, et.al (2010); Hirvela and Du (2013); and Badiozaman (2014).

The prior findings are further divided into three aspects as explained as follows.

\section{STUDENTS' PERSPECTIVE OF PARAPHRASING IN WRITING LITERATURE REVIEW}

Based on the results, three out of six English Department students' paraphrasing output in their respective literature review section of a research proposal, which are the first, the second, and the fifth is categorized as poor paraphrasing while the third, the fourth, and the sixth participant perform an ideal paraphrasing successfully. The classification of these participants' paraphrasing based on the Keck's modified taxonomy of paraphrasing by Badiozaman (2014). The students which classified as poor paraphrasing which they copy almost the entire clause from the original excerpt in their paraphrasing. On the other hand, the other three students' 
paraphrasing classified as moderate revision of paraphrasing due to some changes such as the order of information, the way in re-delivering the ideas, and these students condense the paraphrasing by discarding unnecessary word from the original excerpt.

In accordance to the application of paraphrasing taxonomy, the study finds that all of six participants' paraphrasing quality is determined by their understanding about paraphrasing concept. Basically, these six students have no issue in defining the fundamental concept of paraphrasing. The interview transcripts show identical answers from almost all participants. It is discovered that these students have a similar concept in which they defined it as rendition of the original sentence in their paraphrasing by using their own words. In other words, the paraphrasing concept that these participants comprehend is the essential definition of paraphrasing.

However, overly define paraphrasing in its literal definition has the impact to the paraphrasing skill. This is depicted in the results of the first, second, and fifth participant comprehension regarding to the paraphrasing. The findings revealed a misconception in terms of student' paraphrasing comprehension. This refers to their respond in defining paraphrasing which they answer it in its basic definition. These participants' paraphrasing output is limited to plugging in synonym rather than involving more strategy of paraphrasing (i.e, sentence structuring, word deletion, changing the way of delivering message) in a new form (Kissner, 2006; Driscoll \& Brizee, 2011) with the message from the original passage is still retained (Bailey, 2006). The finding about insufficient knowledge of paraphrasing in this research is similar to the research conducted by Roig (1997) in terms of the issue regarding to the students' misconception of paraphrasing.

The paraphrasing in reviewing literature should comprises more than knowledge transformation rather than knowledge telling, considering the definition of literature review which is the results of analytical reading and it involves more effort to engage with the content of the text (Harvey, 2010; Acheson \& Bond, 2011). In the research finding, these three participants' paraphrasing output identically resemble to a patch writing rather than paraphrasing. This is based on the consideration regarding to the minimal changes in the paraphrased sentence. This result resonates with the explanation from Howard, et.al (2010) which implicitly states that the partial comprehension of paraphrasing may lead one to patch write, "a reproduction, with minor changes to the word and sentence, of the source language.

Interestingly, while these students' perception regarding the concept of paraphrasing is not exactly incorrect, nonetheless, this can be considered as an arguable issue. It should be noticed that this study does not rationalize that the first, second, and fifth participants are committing plagiarism either aware it or not. According to several arguments of some researchers, in some nonnative English countries, patch writing is regarded as a part of learning process (Roig, 1997; Hirvela \& Du, 2013). Still, students are urged to gain deep insight about an eligible paraphrasing due to produce advance writing further.

In contrast to the previous finding, the other three students, which are the third, the fourth, and the sixth participant, are able to define paraphrasing in writing a literature review concept. Based on the correlation between the paraphrasing output and interview results, these three students view paraphrasing as the skill to engage with the text prior to delivering their understanding in a written form. Therefore, these students have no limitation in producing paraphrasing by using their own style. This corresponds to a research conducted by Walker (2008) which states that one must get a bigger picture about some key points in producing a legible paraphrasing. Similarly, some research results resonates to Walker's argument in regards to the process of getting the main idea prior to paraphrase a passage (Ho, 2010; Sun, 2012; Hirvela \& Du, 2013; Badiozaman, 2014).

In addition, the finding in the third, the fourth, and the sixth participant depict the capability of students in comprehending paraphrasing as the process of knowledge transformation (the 
ability to retell the knowledge without being restricted to the pattern of the passage in a text yet retaining the meaning) rather than knowledge telling (the ability to retell an information which restrict one's attempt to express the idea in different style, emphasize more on the structure and the content of source). Several researchers have the similar justification with the finding of this study which affirmed that the essence of paraphrasing in reviewing literature is the ability to transform the knowledge without any meaning shift (Barry, 2006; Howard, et.al, 2010; Hirvela \& Du, 2013). This is due to the involvement of analytic reading in links between paraphrasing and reviewing literature in essence (Amsberry, 2010; Jaidka et.al, 2011).

\section{STUDENTS' PARAPHRASING STRATEGY AND UNDERSTANDING TO THE TEXT}

Aside from the issue in students' knowledge of paraphrasing, the application of students' paraphrasing and the understanding toward source text contributes to the paraphrasing skill. The results in regards to this concern are depicted through the results of the six students' paraphrasing. There are three participants which are the third, fourth, and the fifth participant is able to deliver an accurate paraphrasing. These students have sufficient knowledge of paraphrasing strategy as reflected in the results of paraphrasing. On the other hand, the first, second, and fifth participant did not perform an adequate paraphrasing because of the lack of paraphrasing strategy they know.

This depicts a complex answer to consider that paraphrasing is a complicated skill which requires intensive understanding to comprehend and to apply it their literature review of their research proposal. Issue of changing the word form, due to the inappropriate strategy, is the only problem of inaccurate paraphrasing discovered in this study. The study indicates a correlation of students' linguistics competence, in particular to the process of understanding the meaning through reading and the impact to their writing.

Moreover, based on the output of these participants' writing, there is one similarity of participants' paraphrasing; the strategy applied is quite limited. Due to this, there is no difference between participants' style and the source texts' style in the paraphrasing output. Accordingly, the current study discovers that the first, the second, and the third students have minimum comprehension regarding how many paraphrasing strategy they know. In other words, when students paraphrase a passage, it is more looks the same as taking the word from the sentence (Roig, 1997).

The example about the influence of students reading comprehension to their style of paraphrasing is illustrated in the first participant's paraphrasing sample as depicted as following.

\section{DATA 1: MEANING SHIFT IN PARAPHRASING RESULT}

Original source: What is translation? Often, though not by any means always, it is rendering the meaning of a text into another language in the way the author intended the text.

Paraphrasing version: Newmark (1998) states that translation is transferring the meaning of a text in another meaning by intending the text.

The application of substituting the word "rendering" into "transferring" resulted in meaning shift. The attempt in changing the word class is failed as the meaning in the original text is not the same in the paraphrasing passages. Furthermore, the significant changes in the paraphrased version within students' proposal are quite minimal compared to the source. In other words, the first participant tends to replace several words with synonym from the original source in their proposal yet still retained the keywords. Nevertheless, the paraphrasing results of participants signify that intensive practice particularly in extensive reading is necessary in order 
to produce more successful paraphrasing as suggested by Sun (2012) explained that the level of readable text in certain reading passage affect students writing output; depends on the content of the text.

Several studies indicates a similar report regarding this issue (Ho, 2008; Sun, 2012; Liao \& Tseng; Hirvela \& Du, 2013). These facts are mostly examined in several studies regarding one's behavior toward extensive reading as textual borrowing activity is mostly happened in the ESL/EFL country. Though this research does not address this issue extensively, still, this information worth to be displayed. The concern regarding ESL/EFL, however, will be a valuable report in association to their source-taking behavior.

Still, not all of the participants have same method in restating the passages; three out of six students which are classified as decent paraphrasing in refers to the previous findings (the third, the fourth, and the fifth participant) are able to perform more in attempts to have a qualified paraphrasing based on the paraphrasing strategies they used, most notably is the results of the fourth participants as depicted as follows.

\section{DATA 2: STUDENTS' SUCCESSFUL PARAPHRASING ATTEMPT BY UNDERSTANDING READING TEXT}

Original source: Reading an academic text does not simply involve finding information on the text itself. Rather, it is a process of working with the text. When reading an academic text, the reader recreates the meaning of the text, together with the author.

Paraphrasing version: Hermida (2009, p. 23) explained that reading is an activity when the reader working with the text. For instance, when someone read a text, mean they are trying to get the point about what the author thought.

The fourth participant is not heavily relies on the replacement a word by the synonym in the paraphrasing results (marked in italic). Moreover, this participant did not imitate the entire phrases from the original text but attempt to add some personal flavor in restating the idea in different style. This refers to the last phrases in both passages (recreates the meaning of the text, together with the author in the original excerpt transformed into to get the point about what the author though). The phrase in original passage, specifically "recreates the meaning" and "together with the author" is viewed by this participant as one unity and extract the meaning of these phrases in attempt to produce the own-style phrases as "to get the point about the author thought" in the result of paraphrasing.

This is similar to the results of previous research from Hirvela and Du (2013). They discovered that the more strategy of paraphrasing in one's writing affect the output of paraphrasing, which the research finds that the paraphrasing is a decent one. In paraphrasing, in addition to the insight of the terminology and how to appropriately apply the paraphrasing strategies, another major point to consider is the link between both reading and writing skill (Bissett, 2012). The findings from participant three, participant four, and participant six, depict an interconnection between the linking of reading and writing (in linguistics coverage) and the current research. These findings originated from the classification of Badiozaman's modified paraphrasing taxonomy from Keck. The similarities among these participants refer to the classification of paraphrasing which all of these participants' paraphrasing labeled as moderate revision and the same application of paraphrasing strategy.

\section{THE INTEGRATION OF CITATION MECHANIC IN STUDENTS' PARAPHRASING}

The study finds that students have no issue regarding the authorial identity in their paraphrasing. There is no issue regarding participants' in-text citation within their paraphrasing 
in the proposal (see Appendix 3, p.xi). Furthermore, based on the interview data, the six students reply that they must include a proper in-text citation in their paraphrasing.

Paraphrasing without giving acknowledgement to the author is regarded as plagiarism, especially for the needs of composing an academic paper. One's paraphrasing is not legible if there is no acknowledgement by putting proper citation in their writing. As previously displayed in the findings, the students have no difficulty in putting a proper in-text citation within their paraphrasing. Almost all participants demonstrate their citation knowledge in their paper. This is, perhaps, shaped by their awareness in considering the importance of authorship of the text writing for academic purpose (Roig, 1997; Pecorari, 2008)). Nevertheless, this is contrast to the other researches which indicates that in some of EFL country, a number of misbehavior regarding the implementation of citation is larger in comparison to the ESL one (Lankamp, 2009; Mahmood et.al, 2010; Rabab'ah \& Al-Marshadi, 2013).

Furthermore, it can be inferred that students are, more likely, aware and familiar in terms of how to put an in-text citation in writing an academic essay. This echoing to the interpretation of students' interview results which all six students replied that providing proper reference and its elements in paraphrasing, or any activities related to the scientific essay, is an obligation. This is due to having sufficient experience during all writing-and-research-related courses (Maharsi, 2010). The material of plagiarism is being taught to them in the first or two meetings before advancing to the next material.

Interestingly, while all of the six students have sufficient knowledge about citation mechanic in the paraphrasing, it does not determine that the paraphrasing output will be as decent as the application of in-text citation. This is based on the results of the first, second, and the fifth participant which perform better in putting citation in the paraphrasing yet the output is classified as poor paraphrasing as previously explained. Likewise, the finding is echoing to the Tseng and Tseng (2011) which affirmed the mismatch between students' sufficient knowledge in citing and their results of paraphrasing. However, this is contradict to the Barry's research (2006) which stated that a sufficient mindset regarding the aspect of preventing plagiarism, for instance the citation mechanic, will produce a qualified paraphrasing output as well.

To sum up, the six students' paraphrasing skill might be considered as a complex skill, considering several contradictions in both the results of these students' paraphrasing, the knowledge regarding to the paraphrasing strategy, their understanding toward a reading text, also the influence of citation mechanic in paraphrasing results. There are two classification of students' paraphrasing which are poor paraphrasing and decent paraphrasing based on Keck's modified paraphrasing taxonomy by Badiozaman (2014). The comprehension about paraphrasing is basically the same with the general concept of paraphrasing. However, there are some additional insights of paraphrasing in academic context which are not yet comprehended by the students. Although, there are three among six students perform a decent paraphrasing. Yet, the comprehension regarding to the mechanic of citation has no major impact in three participants' paraphrasing.

It should be noticed that these participants are still a beginner in terms of conducting a scientific research. In responses to this problem, a number of drills are mandatory for students to enhance their writing. Expanding students' insight regarding to the concept of paraphrasing as textual borrowing in academic is also a major issue to be addressed in further researches. This refers to the findings of the three students which successfully involve a proper citation mechanic yet the paraphrasing output is the opposite. Accordingly, this is, probably, shaped by students' mindset which is quite mechanic regarding to the application of citation. However; the current research focus is not considering this issue as the foremost concern.

Overcoming students' difficulty in attempt to paraphrase properly is a notably task for some related institution. The university, specifically to the English Department should facilitate 
students by guide them in academic writing, especially for the content based writing such as paraphrasing, summarizing, reviewing literature, etc. It will help the students in composing the research paper as well as the advisor will only focus to the content of student's research rather than the writing mechanic such as citation mechanic, quotation, etc. Hence, students' academic writing, either research-based writing or any other writing assignments, is expected to have an improvement as well.

\section{CONCLUSIONS AND SUGGESTIONS CONCLUSIONS}

The research concludes that three among six students successfully perform decent paraphrasing, while the other three paraphrasing is the opposite. In terms of the students' insight in defining paraphrasing, all of these six students replied that paraphrasing is the act of restating ideas in their own words. Still, the rest three define paraphrasing in its basic terminology which is heavily relying on synonym substitution rather than restate a passage.

Among six participants, three of them (first, second, and fifth participant) have limited knowledge about paraphrasing strategy affect the paraphrasing output. Yet, the other three participants (third, fourth, and sixth participant) are able to paraphrasing better. This refers to the way of implementing more than strategy of substituting synonym, word deletion, and the comprehension regarding to the content in reading text. As the results, the students' paraphrasing can be classified as an accurate paraphrasing. This is due to the students' attempt in understanding to the original text in their writing.

Furthermore, there are no sign of students' difficulty in responses to the citation mechanic in their paraphrasing. This is, more likely, resonates from their awareness to the elements of implementing proper citation in their writing. The entire citation within students' literature review section, specifically in their paraphrasing, is acceptable. However, this successful attempt in applying proper citation does not help students to produce an ideal paraphrasing. Nevertheless, this issue might be conducted to have an in-depth study regarding the influence of certain mindset or culture to one's writing.

\section{SUGGESTIONS}

Although there are no precise explanations in defining a qualified paraphrase, numerous experts suggest that paraphrasing should be more than synonym replacement from one text to another text. Thus, the academic writers are encouraged to maximize their effort in understanding and applying paraphrasing strategy. Yet, it should be noted that even paraphrasing allow someone to deliver opinion in their style, the message of the original text must be retained in the paraphrasing results. Therefore, students need to pay attention several points in terms of producing an accurate and ideal paraphrasing, considering the result of paraphrasing skill of these students is a complex one.

In order to develop students' comprehension about paraphrasing and the other writing from sources activity, the research suggests that an extensive writing practice is necessary to be undertaken early. This practice is an obligation for students who will conduct a scientific study and who will write an academic essay for the purpose of assignment. It is expected that there is a development once students practice their writing, specifically in paraphrasing. In addition, students must enrich their knowledge regarding all terminology, rules, and mechanics in composed academic paper. By reading several manuals of related topic, students are, at least, able to polish their paraphrasing in terms of implementing more strategies and more awareness to the citation in their work as an act of preventing plagiarism. 
Aside from practicing more in their writing, students are urged to spend more time to read extensively. It will help them to be engaged to the language of the academic paper indirectly as well as expand students' knowledge in terms of how the style of delivering language, consider the result of paraphrasing is the link of one's reading comprehension toward the text and how they put the information in their writing. Still, support from the lecturer and the other related institution is necessary to maximize students' effort, for instance, introducing the concept of paraphrasing earlier to students in writing or research-related subject.

Guiding students in all aspects of content - based writing is necessary to be proposed in university, particularly in writing course. Lecturer is expected to take the major role in conducting this act. Additionally, the institution may use some facilities, for instance the plagiarism-checker software or hiring some competent proofreaders, if available to maximize the effort in enhancing students' writing. Also, it will give major contribution to the improvement of students' self - practice in writing for academic context. Additionally, the advisor will have no issue in guiding students during composing proposal until the final examination.

From the research, more study about paraphrasing and the other behavior in writing from the source is needed. There are several concerns in the aspects of borrowing behavior which is essential to be examined other than paraphrasing. For instance, .For further research, it is recommended to explore students' behavior in addressing the usage of source - use in English department in order to advance both the comprehension of students' reading skill and output of students' writing product. Nevertheless, this research suggests for the further studies to conduct a large-scale study, which encompasses several aspects of textual borrowing behavior or even the intertwining from all of these considerations.

\section{REFERENCES}

Acheson, C., Bond, C. (2011). Writing a literature review. Retrieved from http://slc.otago.ac.nz/files/2013/02/Writing-a-literature-review.pdf

Amsberry, D. (2010). Deconstructing plagiarism: international students and textual borrowing practices. The reference librarian, 51,31-44. Retrieved from http://web.a.ebscohost.com

Badiozaman, I. F. A. (2014). Paraphrasing challenges faced by Malaysian ESL students. Issues in Language Studies, 3(1), 49-69. Retrieved from http://www.ils.unimas.my/media/pdf/v3n2/ilsv3n2_ida.pdf

Bailey, S. (2006). Academic Writing A Handbook for International Students (2nd Ed.). New York: Routledge.

Barry, E. S. (2006). Can paraphrasing practice help students define plagiarism? College Student Journal, 40(2), 377-384. Retrieved from http://search.ebscohost.com/login.aspx?direct=true \&db=a9h\&AN=21375562\&site=ehost-live

Bissett, Y. (2012). Reviewing Literature and Paraphrasing, Study Basics Series. Manchester: University of Salford.

Driscoll, D. L., Brizee, A. (2011). Paraphrase: write it in your own words. Purdue Online Writing Lab. Retrieved from https://owl.english.purdue.edu/owl/resource/563/02/

Harvey, M. (2010). What Is a Literature Review?.doc. Retrieved from: http://www.cs.cmu.edu/ missy/WritingaLiteratureReview.doc

Hirvela, A., Du, Q. (2013). "Why am I paraphrasing?": undergraduate ESL writers' engagement with source-based academic writing and reading. Journal of English for Academic Purposes, 12, 87-98. Retrieved from http://www.vodppl.upm.edu.my/uploads/docs/Paraphrasing_Hirvela.pdf

Ho, C. C. (2008). Teaching appropriate text borrowing practices to law students in an Asian university. Reflections on English Language Teaching, 7(2), 145-154. Retrieved from http://www.nus.edu.sg/celc/research/books/relt/vol7/no2/145-153ho.pdf 
Howard, R. M., Serviss, T., Rodrigue, T. K. (2010). Writing from sources, writing from sentences. Writing and Pedagogy, 2(2), 177-192. Retrieved from http://writing.byu.edu/static/documents/org/1176.pdf

Jaidka, K., Khoo, C., Na, J-C. (2011). Literature review writing: a study of information selection from cited paper. Asia Pacific Conference Library \& Information Education \& Practice, 467-477. Retrieved from http://eprints.uitm.edu.my/3522/1/SP_LRW11_50.pdf

Keck, C. (2006). The use of paraphrase in summary writing: A comparison of L1 and L2 writers. Journal of Second Language Writing, 15. Retrieved February 22, 2009, from www.sciencedirect.com

Kissner, E. (2006). Summarizing, Paraphrasing, and Retelling, Skills for Better Reading, Writing, and Test Taking (pp. iii-9): Heinemann.

Lankamp, R. (2009). ESL student plagiarism: ignorance of the rules or authorial identity problem? Journal of Education and Human Development, 3(1). Retrieved from: http://www.scientificjournals.org/journals2009/articles/1448.pdf

Liao, M. T , \& Tseng, C. Y. (2010). Students' behaviors and views of paraphrasing and inappropriate textual borrowing in an EFL academic setting. Journal of Pan-Pacific Association of Applied Linguistics, 14(2), 187-211.

Lodico, M. G; Spaulding, D. T, \& Voegtle, K. H. (2010). Methods in Educational Research, From Theory to Practice. America: Josey-Bass.

Maharsi, I. (2011). The academic writing experience of undergraduate industrial technology students in Indonesia. Global Perspectives, Local Initiative, 145-158. Retrieved from http://www.nus.edu.sg/celc/research/books/3rdsymposium/145to158-maharsi.pdf

Mahmood, S. T., Mahmood, A., Muhammad, N. K., \& Allaha, B. M. (2010). Intellectual property rights: Conceptual awareness of research students about plagiarism. International Journal of Academic Research, 2(6), 193-198.

McInnis, Lara. (2009). Analyzing English L1 and L2 Paraphrasing Strategies Through Concurrent Verbal Report and Stimulated Recall Protocols.

Pecorari, D. (2008). Academic Writing and Plagiarism: A Linguistics Analysis. 11 York Road, London: Continuum International Publishing Group.

Rabab'ah, G., Al-Marshadi, A. (2013). Integrative vs. non-integrative citations among native and nonnative English writers. International Education Studies, 6(7), 78-87. Retrieved from http://ccsenet.org/journal/index.php/ies/article/download/28446/17024

Roig, M. (1997). Can undergraduate students determine whether text has been plagiarized?. The Psychological Record. 47, 113-122.

Sun, Y. C. (2012). Does text readability matter? A study of paraphrasing and plagiarism in English as a foreign language writing context. Asia-Pacific Education Researcher (De La Salle University Manila), 21(2), 296-306. Retrieved from http://web.ebscohost.com/ehost/pdfviegwer/pdfviewer?sid=549f9793-65cd-43c3-890b$9 \mathrm{cbe} 0842106 \mathrm{c} \% 40$ sessionmgr112\&vid=2\&hid $=112$

USCA Writing Center (2006). Paraphrasing. Retrieved from http://www.usca.edu/asc/pdf/writing\%20room/paraphrasing.pdf

Walker, A. L. (2008). Preventing unintentional plagiarism: A method for strengthening paraphrasing skills. Journal of Instructional Psychology, 35(4), 387-395. Retrieved from http://web.ebscohost.com/ehost/pdfviewer/pdfviewer?sid=51b96dbd-0e82-4611-884a2e175806ae4d\%40sessionmgr198\&vid=1\&hid=113। 